\title{
Comparative Study on Two Modular Spoke-Type PM Machines for In-Wheel Traction Applications
}

\author{
Hengliang Zhang, Wei Hua, David Gerada, Chris Gerada, Yugang Li, Guang Zhang
}

\begin{abstract}
This paper focuses on the comparative analysis of modular spoke-type permanent magnet machines with two magnetization modes, which are referred to as M-I and M-II types. The analytical models of the proposed machines are built based on the simple magneto-motive-force-permeance method. With the help of finite element analysis and the analytical models, magnetic fields in machines with different magnetization modes are compared. Then, taking as a base an existing commercial in-wheel machine used in an electric motorcycle, two proposed machines with different magnetization modes are designed as in-wheel traction machines and compared with respect to electromagnetic torque, flux-weakening performance, over-load capability, etc. The machines are prototyped and experimentally tested to verify the prediction that the M-II machines exhibit a higher torque output while the M-I machines have a wider speed range.
\end{abstract}

Index Terms-AC machines, permanent magnet machines, brushless machines, in-wheel traction.

\section{NOMENCLATURE}

$\mu_{0} \quad$ Permeability of vacuum

$\mu_{r} \quad$ Relative permeability of magnet

$\theta_{p m} \quad$ Magnet arc width

$\theta_{r g}$

$\theta_{r t}$

Rotor module gap arc width

Rotor tooth arc width

$\theta_{r s}$

$\omega$

$B_{r}$

E

$F_{c}, F_{m}$

The relative angle of the rotor to stator

Arc width of stator slot and stator tooth

Mechanical rotational speed

Radial air-gap flux density

Phase back-EMF

Maximum available PM-MMF and actual PM-MMF

$f_{p m}$

$H_{c}$

PM-MMF amplitude

Magnet coercive force

$h_{r t}, h_{p m}$

$i_{d}, i_{q}$

$I_{r}$

$k_{f w}$

$k_{p a}$

$k_{s r}$
$k_{w}$
$L_{d}, L_{q}$
$l_{p m}, \quad l_{\text {stack}}$,
$l_{\text {slot }}, l_{\text {air }}$
$m$
$N_{p m}$
$N_{c}, N_{c t}$
$N_{s}$
$p$
$p_{c o p p e r,}$
$p_{c o r e l o s s}$,
$p_{\text {ecloss }}$
$P_{r g}$
$P_{p m}$
$P_{a i}$,
$P_{\text {aiii }}$,
$R_{o}$
$R_{s o}, R_{r i}$
$R$
$S_{\text {pitch }}$
$T_{\text {em }}$
$U_{d c}$

$k_{s t}$

$L_{d}, L_{q}$

$l_{p m}, \quad l_{\text {stack }}$

$l_{\text {slot }}, l_{\text {air }}$

$m$

$N_{s}$

$p$

$p_{\text {copper }}$

$P_{r g}$

$P_{p}$

$R_{O}$

$R_{s o}, R_{r}$

$R$

$T_{\text {em }}$

$U_{d c}$
Split ratio

Winding factor

$d q$-axes inductance

PM length, stack length, slot length, and

air-gap length

Phase number

Magnet number

Number of turns per phase and per coil

Stator-slot number

Pole-pair number

Copper loss, core loss, and eddy current loss

Permeance of the nonmagnetic support cell between two rotor modules

Permeance of permanent magnet

Permeance of three types of air-gap

Machine outer radius

Stator outer radius, rotor inner radius

Phase resistance

Stator pitch

Electromagnetic torque

DC-voltage

\section{INTRODUCTION}

$\mathrm{W}$ ITH the development of electric vehicles (EVs), in-wheel traction machines have been attracting more and more research interest, due to their high compactness, efficiency, and operational flexibility. Extensive studies are reported on the investigation of in-wheel traction machines' design [1]-[3], analysis [4], [5], optimization [6], [7], and control [8], [9].

To achieve high compactness and efficiency, in-wheel traction machines are always required with high power/torque density and excellent efficiency, which is quite challenging for such low-speed machines. Hence, the in-wheel machine design, including optimization and topology exploration, has always been a popular research topic. In [6], a multi-objective optimization design method of in-wheel switched reluctance machines (SRMs) was developed by using weight factors and base values to achieve the maximum average torque, average torque per copper loss, and average torque per lamination volume. Based on the mechanism of a magnetic gear, a self-decelerating permanent-magnet (PM) in-wheel machine was introduced in [8], where the high-speed rotating field is excited by the armature windings on the inner stator and then modulated to a low-speed rotating field matching with the
Foundation of cupported in part by the National Natural Scienc Research Funds for the Central Universities under Grant 2242019K41002, and in part by the Scientific Research Foundation of Graduate School of Southeas University under Grant YBJJ1834.

Hengliang Zhang, and Wei Hua are with the School of Electrical Engineering, Southeast University, Nanjing, China (email: zhangh12019@163.com, huawei1978@seu.edu.cn).

David Gerada, and Chris Gerada are with University of Nottingham, NG7 2RD, UK (email: David.Gerada@nottingham.ac.uk, Chris.Gerada@nottingham.ac.uk).

Yugang Li, and Guang Zhang are with Wuxi Sine Power Technology Co. Ltd., Wuxi, China (email: lyg80715@163.com, zhguang118@163.com). 
low-speed rotating PM field to achieve high torque. The comparison of PM machines with different rotor and stator topologies was reported in [10], which indicates that the machine with interior magnets and open slots can produce an excellent constant-power-speed-range performance with low manufacturing cost. In [11], a 20-pole-24-slot surface-mounted PM (SPM) machine with consequent-pole rotor was assembled to improve the reluctance torque and field-weakening capability. In [12], a DC-field-excited axial-flux doubly salient machine for in-wheel direct drive applications was proposed to achieve an improved torque density and widened speed range. Besides, due to the high torque density and simple rotor structure [13], flux-switching PM (FSPM) machines are also designed and optimized for in-wheel traction systems in [14], [15], where stators are modified to get more slot space, higher pole-pair numbers, and hence high torque.

Overall, the design and optimization of in-wheel machines can be summarized as follows: improving the active air-gap area (e.g., axial-flux machines), enhancing the air-gap flux density (e.g., FSPM machines), increasing the pole-pair number (e.g., magnetic gear-based PM machines), and enlarging the armature winding space (e.g., open slot). However, when making a choice as to which topology to implement, both performance and manufacturing cost should be considered. Axial-flux machines and magnetic gear-based PM machines are difficult to assemble; FSPM machines use too many magnets and exhibit limited over-load capability; wound-field and switched reluctance machines' torque densities are lower than those of PM machines [16]. Hence, the topology exploration is still a hot research point of in-wheel traction machines.

In [17], the modular spoke-type PM (MSTPM) machines are first introduced. The MSTPM machines are inspired by FSPM machines, but sandwiched magnets are moved away from the stator to the rotor to alleviate the serious saturation in stator teeth and achieve an improved over-load capability. It is reported that the MSTPM machines exhibit a better torque characteristic, higher efficiency, and much stronger flux-weakening capability than the SPM machines [18]. Therefore, the MSTPM machines are certainly promising candidates for in-wheel traction applications. The operation principle, back electromotive force (EMF), and stator-slot/rotor-pole combination of MSTPM machines are investigated in [19]. Further, special design considerations of the MSTPM machines, including the elimination of even-order back-EMF harmonics and unbalance magnetic force (UMF), are discussed in [20], [21]. In addition, the analytical solution of air-gap fields of MSTPM machines is deduced based on conformal mapping in [18]. Moreover, two different magnetization modes of MSTPM machines are firstly reported in [22]. It is found that MSTPM machines with two magnetization modes exhibit different fundamental frequencies, different field harmonic spectra, and hence different stator-slot/rotor-pole combinations.

The analytical solution of the radial air-gap flux-density in the MSTPM machines with different magnetization modes is still not reported in existing literature. In addition, the torque-sizing equation, the rotor structure modification, and the split ratio optimization are still not analyzed. Furthermore, none of the available literature compares the load performance and flux-weakening capability of the two types of MSTPM machines. Hence, this paper is aimed at solving the above-mentioned problems of MSTPM machines by deriving the analytical torque-sizing equations with different magnetization modes, comparing the two MSTPM machines with optimized rotor structures and split ratios. Finally, the merits and demerits of the two types of MSTPM machines for in-wheel traction applications will be revealed.

This paper has been organized in the following manner. At first, the analytical models of two MSTPM machines are built based on the simple magneto-motive-force (MMF) -permeance method. Then, based on the proposed analytical model and finite element analysis (FEA), two MSTPM machines with the same dimension and power source supply are designed as in-wheel traction machines and compared with respect to the air-gap field harmonic spectrum, back-EMF, average torque, over-load capability, constant power speed range, and efficiency. Finally, prototype machines are manufactured and tested to verify the analytical and FEA prediction.

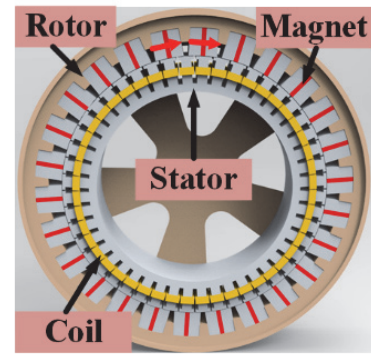

(a)

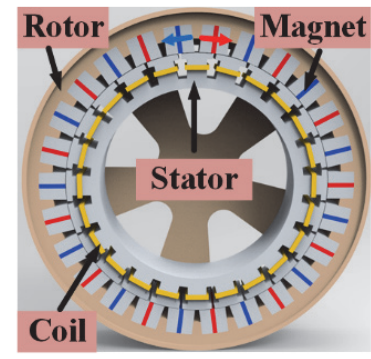

(b)
Fig. 1. MSTPM machines with two magnetization modes. (a) M-I MSTPM machine. (b) M-II MSTPM machine.

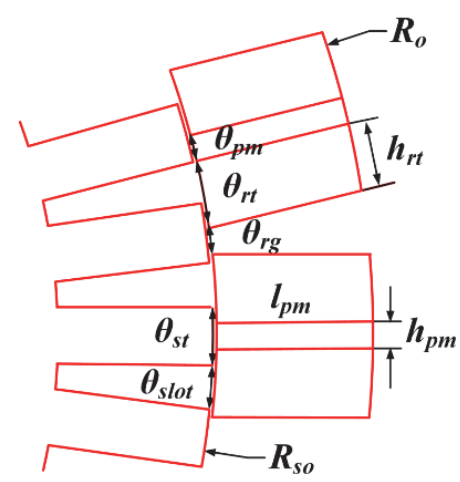

Fig. 2. Cross-sectional structure of MSTPM machines marked with key symbols.

\section{TOPOLOGY AND MATHEMATICAL MODEL}

\section{A. Machine Topology}

As shown in Fig. 1, the MSTPM machine's rotor consists of a wheel rim and rotor modules including rotor teeth and sandwiched magnets. The adjacent two rotor modules have two different magnetization modes which in this paper are referred to as M-I and M-II modes. The M-I mode is such that adjacent 
magnets are magnetized in the same direction, as shown in Fig. 1 (a); the M-II mode is such that each magnet is magnetized in the opposite direction to the adjacent one, as shown by the arrows in Fig. 1 (b). All rotor modules are inserted into the wheel rim, resulting in high compactness and reliable force transmission. In order to obtain a high winding packing factor and low phase resistance, fractional-slot concentrated windings are used. The cross-sectional structure marked with key symbols is illustrated in Fig. 2.

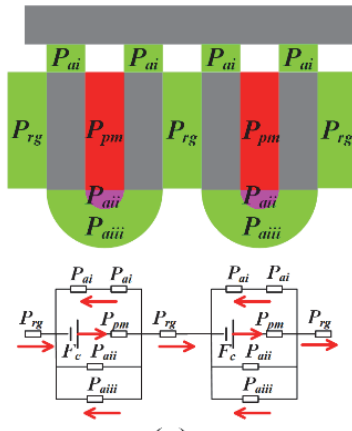

(a)
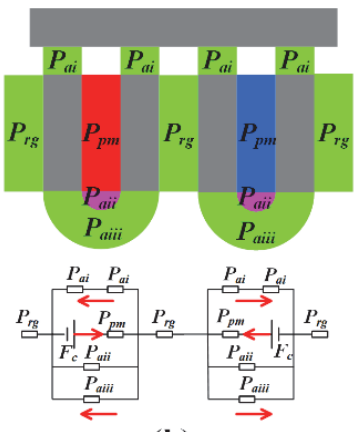

(b)
Fig. 3. Magnetic circuit models of MSTPM machines. (a) M-I. (b) M-II.

\section{B. Magnetic Circuit Model}

The use of magnetic circuit models is a popular method used for the analysis of electrical machines [23], especially in the derivation of the torque-sizing equation. The magnetic circuit models of unslotted M-I and M-II MSTPM machines are shown in Fig. 3. Except for the silicon steel sheets which are assumed to have infinite permeability, there are 5 types of magnetic flux path whose permeance can be calculated by following formulae.

The magnet permeance $P_{p m}$ is

$$
P_{p m}=\mu_{r} \mu_{0} \frac{l_{p m} l_{\text {stack }}}{h_{p m}}
$$

where $l_{p m}$ and $h_{p m}$ are the length and width of the magnet, respectively, $l_{\text {stack }}$ is the active stack length, $\mu_{r}$ is the relative permeability of the magnet, and $\mu_{0}$ is the permeability of vacuum.

The permeance of the nonmagnetic support cell between each two rotor modules $P_{r g}$ is

$$
P_{r g}=\mu_{0} \frac{l_{\text {stack }}}{\theta_{r g}} \ln \left(\frac{R_{o}}{R_{r i}}\right)
$$

where $\theta_{r g}$ is the rotor module gap arc width, $R_{o}$ is the machine outer radius, and $R_{r i}$ is the rotor inner radius.

The permeance of air-gap area I $P_{a i}$ is

$$
P_{a i}=\mu_{0} \frac{l_{\text {stack }} h_{r t}}{l_{\text {air }} k_{c}}
$$

where $h_{r t}$ is the width of the rotor tooth, $l_{\text {air }}$ is the air-gap length. To account for the influence of slot-opening, the Carter coefficient $k_{c}$ is used in the calculation of $P_{a i}$, and $k_{c}$ is obtained by [24]

$$
k_{c}=\frac{S_{\text {pitch }}}{S_{\text {pitch }}-l_{\text {slot }}+\frac{4 l_{\text {air }}}{\pi} \ln \left(1+\frac{\pi}{4} \frac{l_{\text {slot }}}{l_{\text {air }}}\right)}
$$

where $S_{\text {pitch }}$ is the stator pitch, $l_{\text {slot }}$ is the slot length.

The permeance of air-gap area II $P_{a i i}$ is

$$
P_{\text {aii }}=0.26 \mu_{0} l_{\text {stack }}
$$

The permeance of air-gap area III $P_{\text {aiii }}$ is

$$
P_{\text {aiii }}=\mu_{0} \frac{l_{\text {stack }}}{\pi} \ln \left(\frac{h_{p m}+2 h_{r t}}{h_{p m}}\right)
$$

Furthermore, the maximum available PM-MMF is

$$
F_{c}=H_{c} * h_{p m}
$$

where $H_{c}$ is the magnet coercive force.

On the basis of (1)-(7), the PM-MMF-permeance models of the two MSTPM machines considered in this paper are further proposed in Parts $\mathrm{C}$ to analyze the air-gap field and deduce the torque-sizing equation. It should be pointed out that the PM-MMF-permeance model has been extensively employed to analyze air-gap field, guide machine design and optimization [25]-[27].

\section{PM-MMF-Permeance Model}

Fig. 4 shows PM-MMF and air-gap permeance waveforms of the two types of MSTPM machines, where $\theta_{r t}$ is the rotor tooth arc width, $\theta_{p m}$ is the magnet arc width, and $\theta_{r g}$ is the rotor module gap arc width.

As shown in Fig. 4 (a), it is easy to deduce that each rotor module produces one pair of magnetic poles in M-I MSTPM machines. However, in M-II MSTPM machine, two pieces of rotor modules are needed to produce one pair of magnetic poles. Hence, in M-I MSTPM machine, the pole-pair number $p$ equals the magnet number $N_{p m}$; while in M-II MSTPM machine, $p$ is equal to half of $N_{p m}$.

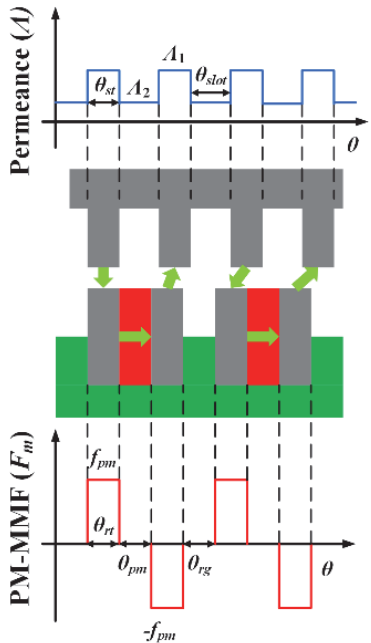

(a)

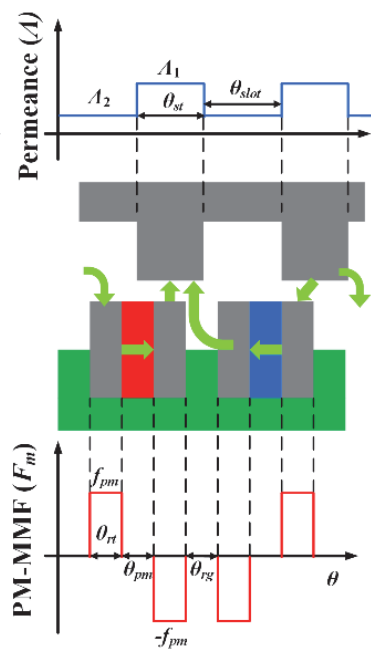

(b)
Fig. 4. PM-MMF-permeance models of MSTPM machines. (a) M-I. (b) M-II

Furthermore, from Fig. 4 (a), the magnet arc width $\theta_{p m}$ should equal the rotor module gap arc width $\theta_{r g}$ in order to achieve the magnetic symmetry in M-I MSTPM machines. However, M-II MSTPM machines do not have this constraint. This important difference will result in different optimal 
geometric parameters, which will be discussed in Section III, Part A.

Based on the magnetic circuit model shown in Fig. 3, the $f_{p m}$ of M-I and M-II MSTPM machines is obtained from

$$
f_{p m}=\frac{F_{c} * P_{p m}}{P_{a i}+2 P_{a i i}+2 P_{a i i i}+P_{r g}+2 P_{p m}}
$$

and

$$
f_{p m}=\frac{F_{c} * P_{p m}}{P_{a i}+2 P_{a i i}+2 P_{a i i i}+2 P_{p m}}
$$

respectively.

The air-gap permeance distribution is simplified as a two-valued function expressed by

$$
\Lambda= \begin{cases}\Lambda_{1} & 0 \leq \theta<\theta_{s t} \\ \Lambda_{2} & \theta_{s t} \leq \theta<\frac{2 \pi}{N_{s}}\end{cases}
$$

where $\theta_{s t}$ is the stator tooth arc width, $\theta_{\text {slot }}$ is the stator slot arc width. Based on the conformal mapping method [27], $\Lambda_{1}$ and $\Lambda_{2}$ can be calculated by

$$
\begin{gathered}
\Lambda_{1}=\frac{\mu_{0}}{l_{\text {air }}} \\
\Lambda_{2}=\frac{l_{\text {air }}}{\sqrt{l_{\text {air }}^{2}+\frac{l_{\text {slot }}^{2}}{4}}} \times \Lambda_{1}
\end{gathered}
$$

Then, the radial air-gap flux density $B_{r}$ due to magnets is

$$
B_{r}=F_{m} * \Lambda
$$

Based on the air-gap field modulation theory [25]-[27], it is found that the fundamental back-EMF in MSTPM machines is induced by multiple field harmonics, of which the $p$-th and $\left(p+N_{s}\right)$-th field harmonics are the dominant harmonics.

Based on Fourier series, the $p$-th fundamental flux density of M-I and M-II MSTPM machines can be obtained from

$$
B_{p}=\frac{2 N_{s} f_{p m} \sin \left(\frac{p \theta_{r t}}{2}\right)\left(\Lambda_{2} \theta_{\text {slot }}+\Lambda_{1} \theta_{s t}\right)}{\pi^{2}}
$$

and

$$
\begin{aligned}
& B_{p}= \\
& \qquad \frac{2 N_{s} f_{p m}\left[\cos \left(\frac{p \theta_{p m}}{2}\right)-\sin \left(\frac{p \theta_{r g}}{2}\right)\right]\left(\Lambda_{2} \theta_{\text {slot }}+\Lambda_{1} \theta_{s t}\right)}{\pi^{2}}
\end{aligned}
$$

respectively.

The $\left(p+N_{s}\right)$-th fundamental flux density of M-I and M-II MSTPM machines is

$$
B_{p+N_{s}}=\frac{4 f_{p m} \sin \left(\frac{p \theta_{r t}}{2}\right)\left(\Lambda_{1}-\Lambda_{2}\right) \sqrt{1+\sin \left(N_{s} \theta_{s t}\right)^{2}}}{\pi^{2}}
$$

and

$$
B_{p+N_{s}}=\frac{4 f_{p m}\left[\cos \left(\frac{p \theta_{p m}}{2}\right)-\sin \left(\frac{p \theta_{r g}}{2}\right)\right]}{\pi} \times \frac{\left(\Lambda_{1}-\Lambda_{2}\right) \sqrt{1+\sin \left(N_{s} \theta_{s t}\right)^{2}}}{\pi}
$$

, respectively.

On the basis of (14)-(17), the average torque of MSTPM machines is

$$
\begin{aligned}
\left.T_{e m}=\sqrt{\frac{2}{3} m N_{c} k_{w} R_{\text {so }} l_{\text {stack }}\left(B_{p}+\frac{p}{p+N_{s}}\right.} B_{p+N_{s}}\right) i_{q} \\
+p i_{d} i_{q}\left(L_{d}-L_{q}\right)(18)
\end{aligned}
$$

where $k_{w}$ is the winding factor which can be calculated as in [29], $N_{c}$ is the number of turns per phase, and $m$ is the phase number. The first part is the torque produced by the interaction of PM-field and $q$-axis armature current, while the second part is the reluctance torque. It should be noted that the $i_{d}$ is negative under flux-weakening operation.

TABLE I

KEY PARAMETERS OF TWO MSTPM MACHINES

\begin{tabular}{ccc}
\hline \hline Parameter & M-I MSTPM & M-II MSTPM \\
\hline Magnet type & N35SH \\
Slot number & 48 & 24 \\
Phase number & 3 & \\
Magnet number & 26 \\
Slot number per pole per phase & $4 / 13$ \\
Coil turn per phase & 48 \\
Outer radius & $138 \mathrm{~mm}$ \\
Air-gap length & $0.5 \mathrm{~mm}$ \\
Stack length & $45 \mathrm{~mm}$ \\
Stator outer radius & $114.5 \mathrm{~mm}$ \\
Rotor tooth arc width & $4.98^{\circ}$ \\
Rotor module gap arc width & $1.94^{\circ}$ \\
Magnet arc width & $1.94^{\circ}$ \\
Phase current (RMS) & $30 \mathrm{~A}$ \\
\hline \hline
\end{tabular}

To ensure the model can be solved without any help of numerical method, some complex phenomena are ignored in the proposed model. The ignored phenomena include the tangential air-gap flux density, saturation, temperature fluctuation, and three-dimensional effects.

\section{FEA Verification}

To verify the analytical model, two FEA models of 3-phase M-I and M-II MSTPM machines with the key parameters listed in Table I are built, and the finite permeability of silicon steel sheets is considered. Except for the different magnetization modes, these two MSTPM machines have the same rotor structure. Then their air-gap field harmonic spectra are calculated and shown in Fig. 5.

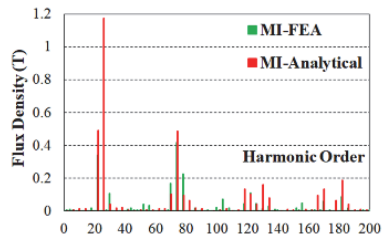

(a)

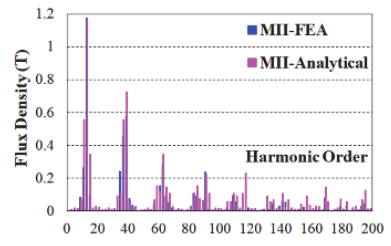

(b)
Fig. 5. Analytical and FEA-calculated air-gap field harmonic spectra of M-I and M-II MSTPM machines due to magnets only. (a) M-I. (b) M-II.

According to the analytical results, the dominant working harmonics of M-I MSTPM machine are the $26^{\text {th }}$ and $74^{\text {th }}$, while for the M-II MSTPM machines they are the $13^{\text {th }}$ and $37^{\text {th }}$ field harmonics. As shown in Table II, a good agreement is achieved between analytical and FEA-calculated dominant working harmonics. The difference between analytical and FEA-calculated average torque is less than $2.5 \%$. Since the analytical model ignores the tangential air-gap flux density which is critical for the torque ripple, it is not suggested to 
calculate the torque ripple by using the proposed analytical model.

Owing to the simplification of PM-MMF and permeance waveforms, amplitudes of nondominant field harmonics calculated by PM-MMF-permeance model are a bit different from those computed by FEA. However, we can still observe that the M-II MSTPM machine has richer nondominant harmonics than the M-I MSTPM machine, according to both the analytical and FEA results.

Considering the analytical model only provides initial results at the so-called pre-design stage, a good accuracy has been achieved by using the PM-MMF-permeance model.

TABLE II

DOMINANT HARMONIC AND TORQUE OF ANALYTICAL AND FEA RESULTS

\begin{tabular}{ccccc}
\hline \hline & \multicolumn{2}{c}{ M-I } & \multicolumn{2}{c}{ M-II } \\
& Analytical & FEA & Analytical & FEA \\
\hline $13^{\text {th }}$ harmonic & - & - & $1.16 \mathrm{~T}$ & $1.17 \mathrm{~T}$ \\
$26^{\text {th }}$ harmonic & $1.17 \mathrm{~T}$ & $1.16 \mathrm{~T}$ & - & - \\
$37^{\text {th }}$ harmonic & - & - & $0.55 \mathrm{~T}$ & $0.45 \mathrm{~T}$ \\
$74^{\text {th }}$ harmonic & $0.48 \mathrm{~T}$ & $0.42 \mathrm{~T}$ & - & - \\
$T_{e m}$ & $40 \mathrm{Nm}$ & $39 \mathrm{Nm}$ & $40.4 \mathrm{Nm}$ & $40 \mathrm{Nm}$ \\
\hline \hline
\end{tabular}

TABLE III

KEY CONSTRAINTS OF TWO MSTPM MACHINES

\begin{tabular}{cc}
\hline \hline Parameter & Value \\
\hline DC-voltage & $72 \mathrm{~V}$ \\
Rated current (RMS) & $30 \mathrm{~A}$ \\
Rated current density (RMS) & $5 \mathrm{~A} / \mathrm{mm}^{2}$ \\
Outer Radius & $138 \mathrm{~mm}$ \\
Stack length & $45 \mathrm{~mm}$ \\
Slot fill factor (pure copper) & 0.35 \\
Rated speed & $480 \mathrm{r} / \mathrm{min}$ \\
\hline \hline
\end{tabular}

\section{COMPARISON}

In this section, two M-I and M-II MSTPM machines with 26 pieces of magnets are designed for electric motorcycles. The design constraints are listed in Table III. Since the average torque is the most important performance index of electric motorcycles, the two M-I and M-II MSTPM machines are optimized to achieve the maximum average torque.

\section{E. Influence of Split Ratio}

The split ratio $k_{s r}$ of the MSTPM machine is the ratio of stator outer radius $R_{s o}$ to machine outer radius $R_{o}$, i.e.

$$
k_{s r}=\frac{R_{s o}}{R_{o}}
$$

According to (1)-(6), (8)-(9), and (14)-(18), the split ratio has a significant influence on the dominant working field harmonic and electromagnetic torque. Hence, finding the optimal split ratio is important for achieving high torque density.

Before optimizing the split ratio, the rotor structures of M-I and M-II machines should be optimized to achieve few nondominant field harmonics and high working field harmonics. With the help of equations (1)-(18), the radial air-gap flux density distribution in M-I and M-II MSTPM machines can be calculated. Based on Fourier analysis, the field harmonic spectra of two types of MSTPM machines are computed. The optimal rotor structure of the M-I MSTPM machine is $\theta_{p m}: \theta_{r g}: \theta_{r t}=0.14: 0.14: 0.72$, while for the M-II machine $\theta_{p m}: \theta_{r g}: \theta_{r t}=0.28: 0: 0.36$. It is worth mentioning, according to (2), (9), (15), and (17), $\theta_{\text {rg }}$ can enrich nondominant harmonics and weaken the dominant working harmonic in M-II machines, hence $\theta_{r g}$ should be as small as possible to achieve a high torque/power density.

Based on the optimal rotor structures and dimensional constraints listed in Table III, electromagnetic torque versus split ratio curves of M-I and M-II MSTPM machines with the injection of $5 \mathrm{~A} / \mathrm{mm}^{2}$ (RMS) current density are calculated and shown in Fig. 6.

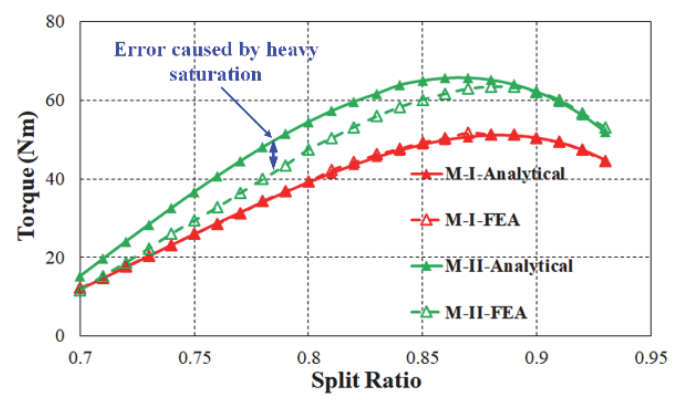

Fig. 6. Analytical and FEA predicted torque versus split ratio of M-I and M-II MSTPM machines with $5 \mathrm{~A} / \mathrm{mm} 2$ current density injection.

From Fig. 6, the analytical torque versus split ratio curve of the M-I MSTPM machine is very close to the FEA-calculated results. The difference is less than $1 \%$, which reflects the high accuracy of the analytical model. If the current is not limited, the M-I MSTPM machine with the injection of $5 \mathrm{~A} / \mathrm{mm}^{2}$ (RMS) current density can achieve the peak torque when the split ratio is 0.88 . To obtain a high torque, the suggested split ratio region of the M-I MSTPM machine is in the range $(0.83,0.93)$.

For the M-II MSTPM machine, there is a difference higher than $10 \%$ between analytical and FEA-calculated curves when the split ratio is less than 0.83 . When the split ratio is small, too many magnets are used which causes heavy saturation in the stator and rotor teeth. The heavy saturation results in the non-negligible error of analytical model. When the split ratio is more than 0.85 , the saturation is alleviated, so the analytical predictions are closer to the FEA results.

From Fig. 6, the M-II MSTPM machine with the injection of $5 \mathrm{~A} / \mathrm{mm}^{2}$ (RMS) current density can achieve the theoretical peak torque when the split ratio is equal to 0.88 . The suggested split ratio region of the M-II MSTPM machine is thus $(0.85$, $0.91)$ where the saturation is light, and the average torque is high.

Overall, from both the analytical and FEA results, the M-II MSTPM machine can produce a higher torque than the M-I MSTPM with the same current density injection.

\section{F. Split Ratio Determination}

The constraints of DC-voltage and phase current are not taken into account in deriving Fig.6. However, in machine design, the constraints of machine dimension, current density, DC-voltage, and phase current should be considered. From that point, the curves of torque versus split ratio are calculated as shown in Fig. 7. In the calculation, the number of turns per phase is adjusted to match the $72 \mathrm{~V} \mathrm{DC}$-voltage. 
It is found that the analytical results of the M-I MSTPM machine are very close to the FEA results. For the M-II MSTPM machine, there is a difference higher than $10 \%$ between analytical and FEA-calculated curves when the split ratio is less than 0.86 , resulting from the pronounced saturation. However, when the split ratio is more than 0.86 , the analytical and FEA-calculated results of M-II MSTPM machine are similar.

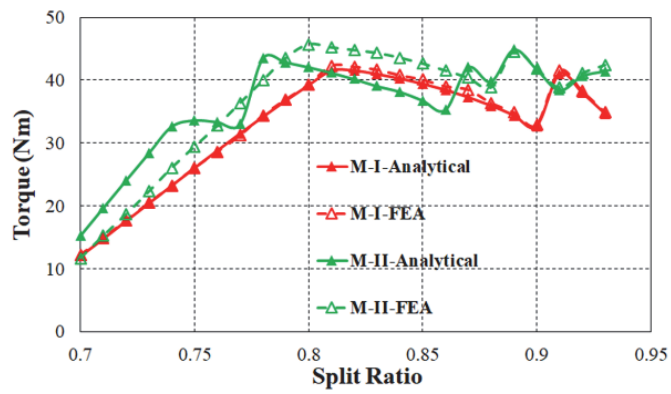

Fig. 7. Analytical and FEA predicted torque versus split ratio of M-I and M-II MSTPM machines with limited DC-voltage and current.

From Fig.7, the M-I MSTPM machine achieves its peak torque when the split ratio varies from 0.81 to 0.83 or is equal to 0.91. For the M-II MSTPM machine, the peak torque is obtained when the split ratio is 0.89 . In order to achieve the high average torque, the split ratio of M-I and M-II MSTPM machine are set as 0.83 and 0.89 , and the corresponding numbers of turns per coil are 3 and 6 . More details of the two designed M-I and M-II MSTPM machines are listed in Table IV.

TABLE IV

\begin{tabular}{ccc} 
KEY PARAMETERS OF TWO MSTPM MACHINES \\
\hline \hline Design Parameter & M-I & M-II \\
\hline Magnet number & \multicolumn{2}{c}{26} \\
Stator-slot number & 48 & 24 \\
Number of turns per coil & 3 & 6 \\
Number of turns per phase & \multicolumn{2}{c}{48} \\
Split ratio & 0.83 & 0.89 \\
Rotor module gap arc width & $1.94^{\circ}$ & 0 \\
\hline \hline
\end{tabular}

\section{G. Open-Circuit Performance}

Fig. 8 shows the open-circuit self-inductance and phase back-EMF (at $480 \mathrm{r} / \mathrm{min}$ ) waveforms of the M-I and M-II MSTPM machines. It is found that the M-II MSTPM machine has a slightly higher phase back-EMF than the M-I MSTPM machine. According to the analysis in Section II, the dominant working field harmonics of M-I and M-II MSTPM machines with 26 magnets are the $26^{\text {th }}$ and $13^{\text {th }}$ field harmonic, respectively, which means that their pole-pair numbers are 26 and 13. This explains why the phase flux linkage in the M-II machine is double that of the M-I machine but their phase back-EMF amplitudes are close at the same rotating speed.

From Fig. 8 and Table V, the $d$ - \& $q$-axes inductances of the M-I machine are $0.216 \mathrm{mH}$ and $0.24 \mathrm{mH}$, while those of the M-II machine are $0.304 \mathrm{mH}$ and $0.417 \mathrm{mH}$, respectively. Based on the rated phase back-EMF and current, the per-unit values of the inductances in the two MSTPM machines are calculated and listed in Table V. It is predicted that the M-I MSTPM machine features a stronger flux-weakening capability than the
M-II MSTPM machine due to a higher per-unit value of $d$-axis inductance.

In addition, thanks to a higher least common multiple (LCM) of stator-slot number and pole-pair number, the M-I machine has a lower cogging torque [30], as shown in Fig. 9.

TABLE V

OPEN-CIRCUIT PERFormanCE OF TWO MSTPM MACHINES

\begin{tabular}{ccc}
\hline \hline Performance & M-I & M-II \\
\hline Fundamental phase back-EMF & $37 \mathrm{~V}$ & $38 \mathrm{~V}$ \\
Fundamental phase flux linkage & $28.3 \mathrm{mWb}$ & $58.3 \mathrm{mWb}$ \\
$L_{d}$ & $0.216 \mathrm{mH}$ & $0.304 \mathrm{mH}$ \\
$L_{d}$ (per-unit value) & 0.32 & 0.22 \\
$L_{q}$ & $0.24 \mathrm{mH}$ & $0.417 \mathrm{mH}$ \\
$L_{q}$ (per-unit value) & 0.36 & 0.30 \\
Cogging torque amplitude & $0.3 \mathrm{Nm}$ & $1 \mathrm{Nm}$ \\
\hline \hline
\end{tabular}

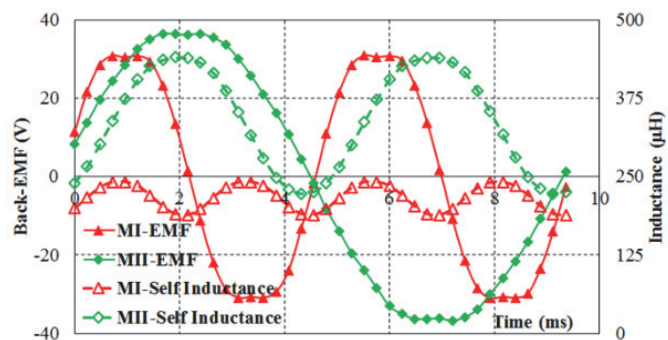

Fig. 8. FEA-calculated phase back-EMF and self-inductance waveforms of $\mathrm{M}-\mathrm{I}$ and M-II MSTPM machines at $480 \mathrm{r} / \mathrm{min}$.

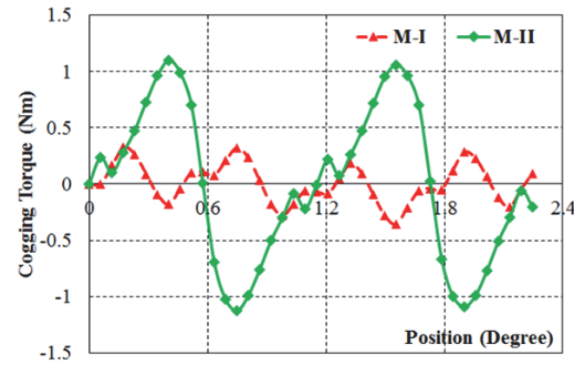

Fig. 9. FEA-calculated cogging torque of two MSTPM machines.

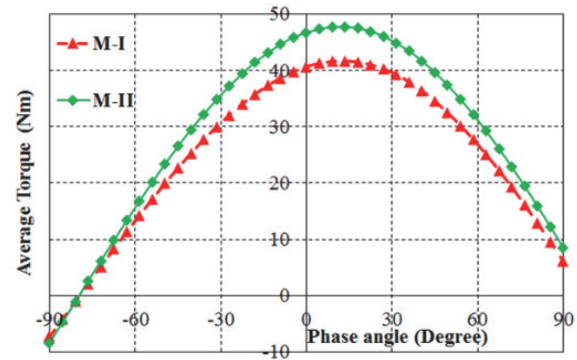

Fig. 10. Average torque versus phase current angle curves of M-I and M-II MSTPM machines with 30 A (RMS) current injection.

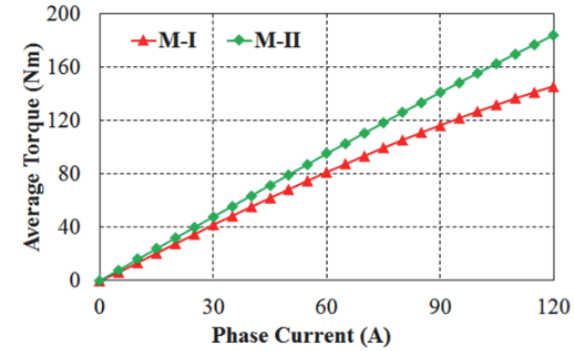

Fig. 11. Torque-current curves of M-I and M-II MSTPM machines. 


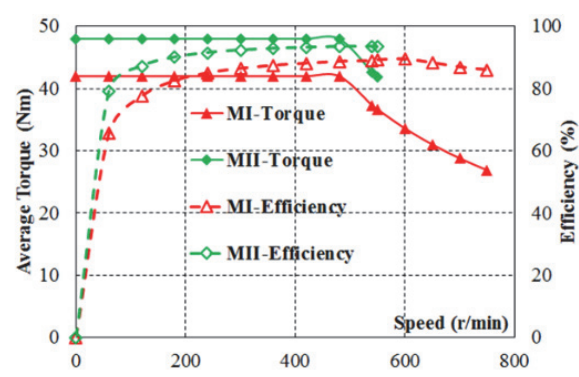

Fig. 12. Torque- and efficiency-speed curves of M-I and M-II MSTPM machines under rated current injection.

\section{H. On-Load Performance}

According to the preceding open-circuit analysis, the $d$-axis inductance is different from the $q$-axis inductance in both of M-I and M-II MSTPM machines. Hence, the M-I and M-II MSTPM machines can produce reluctance torque during flux-weakening operations. Under the rated current (30 $\mathrm{A}(\mathrm{RMS})$ ) injection, the curves of average torque versus phase current angle of two MSTPM machines are calculated as shown in Fig. 10. It is found that the two MSTPM machines have the same optimal current angle of $13.5^{\circ}$, where the M-I and M-II machines can produce $42 \mathrm{Nm}$ and $48 \mathrm{Nm}$, respectively.

Based on the optimal current angle, the torque versus phase current (RMS value) curves are calculated and shown in Fig. 11 Obviously, the M-II machine exhibits a more linear torque-current curve than the M-I machine. When $120 \mathrm{~A}(\mathrm{RMS})$ current is injected, the M-I machine produces $146 \mathrm{Nm}$ but the M-II machine provides $184.2 \mathrm{Nm}$. Hence, the M-II MSTPM machine exhibits a better over-load capability, which is quite important for in-wheel traction machines.

Furthermore, due to the strong PM flux linkage, the PM machine is hard to achieve wide speed operation under limited DC-voltage. Based on Park's Transformation, the constant-power region and theoretical maximum speed can be predicted according to the DC-voltage, rated current, PM flux linkage, $d q$-axes inductance, and phase resistance. The calculated phase resistances at $75^{\circ} \mathrm{C}$ of M-I and M-II MSTPM machine are $47.8 \mathrm{~m} \Omega$ and $26 \mathrm{~m} \Omega$, respectively. The correspondingly predicted constant-power region of M-I and M-II MSTPM machines are 480 750 r/min, and 480 550 r/min, respectively. As evident, the M-I machine has a wider constant-power region which is favorable for in-wheel traction applications where wide speed range is often required.

On the basis of theoretical and FEA calculation, torque- and efficiency-speed curves of the M-I and M-II MSTPM machines are obtained and shown in Fig. 12. In the constant-torque region, the $\mathrm{M}$-II machine can produce $48 \mathrm{Nm}$ which is $14 \%$ higher than the M-I machine (42 Nm). Besides, the M-II machine has a higher efficiency than the M-I machine when copper loss, core loss, and eddy current loss are taken into consideration. At the rated point, the M-I machine can provide $42 \mathrm{Nm}$ at $480 \mathrm{r} / \mathrm{min}$ with an efficiency of $89 \%$, and the M-II machine can produce $48 \mathrm{Nm}$ at $480 \mathrm{r} / \mathrm{min}$ with a higher efficiency of $93.4 \%$.

The performance of two MSTPM machines is finally compared in Table VI where the better indexes are marked with the green background. It is concluded that the M-I MSTPM machine has a wider constant speed-range thanks to a higher per-unit inductance, while the M-II MSTPM machine exhibits a higher efficiency, better torque/ power output, and stronger over-load capability.

TABLE VI

FINAL COMPARISON OF TWO MSTPM MACHINES Performar

\begin{tabular}{ccc}
\hline \hline Performance & M-I & M-II \\
\hline Torque (rated speed) & $42 \mathrm{Nm}$ & $48 \mathrm{Nm}$ \\
Over-load torque & $146 \mathrm{Nm}$ & $184.2 \mathrm{Nm}$ \\
Power (rated) & $2.1 \mathrm{~kW}$ & $2.4 \mathrm{~kW}$ \\
Torque density (rated) & $15.6 \mathrm{Nm} / \mathrm{L}$ & $17.8 \mathrm{Nm} / \mathrm{L}$ \\
Power density (rated) & $0.78 \mathrm{~kW} / \mathrm{L}$ & $0.89 \mathrm{~kW} / \mathrm{L}$ \\
Magnet mass & $0.67 \mathrm{~kg}$ & $1.05 \mathrm{~kg}$ \\
Efficiency (rated speed) & $89 \%$ & $93.4 \%$ \\
Power factor (rated speed) & 0.93 & 0.97 \\
$L_{d}$ (per-unit value) & 0.32 & 0.22 \\
$L_{q}$ (per-unit value) & 0.36 & 0.30 \\
Armature resistance (per-unit value) & 0.055 & 0.029 \\
Constant-power region & $480 \sim 750 \mathrm{r} / \mathrm{min}$ & $480 \sim 550 \mathrm{r} / \mathrm{min}$ \\
\hline \hline
\end{tabular}

\section{EXPERIMENTAL VALIDATIONS}

To verify the analysis and prediction, three prototyped MSTPM machines are manufactured and tested. They are M-I MSTPM machine with laminated SiFe-made rotor teeth, M-II MSTPM machine with laminated SiFe-made rotor teeth, and an M-II MSTPM machine with solid-iron-made rotor teeth, as shown in Figs. 13 and 14. Here, the M-II MSTPM machine with solid-iron-made rotor teeth is assembled to explore the possibility of a low-cost MSTPM machine version.

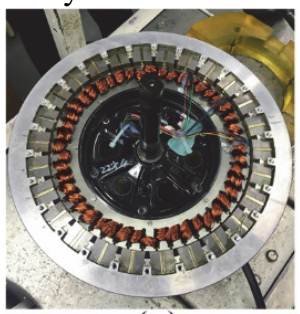

(a)

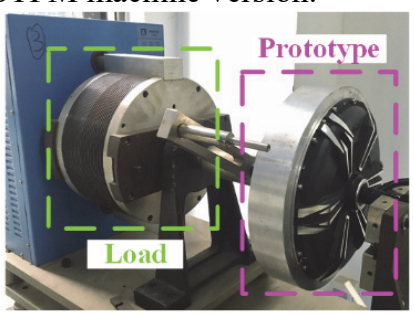

(b)
Fig. 13. M-I MSTPM prototype machine. (a) Prototype machine. (b) Experimental platform.

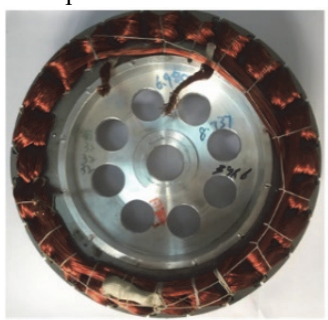

(a)

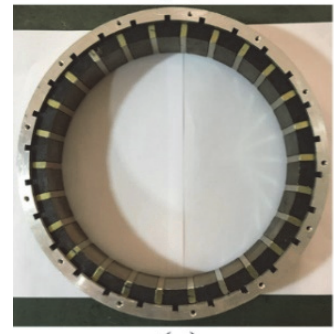

(c)

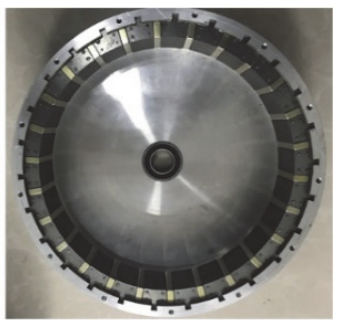

(b)

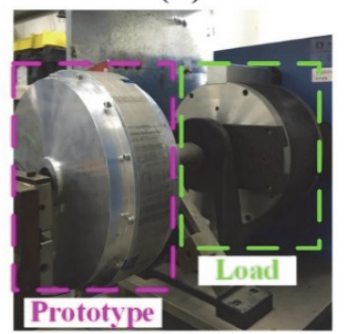

(d)
Fig. 14. M-II MSTPM prototype machine. (a) Stator. (b) Laminated SiFe-made rotor. (c) Solid-iron-made rotor. (d) Experimental platform. 


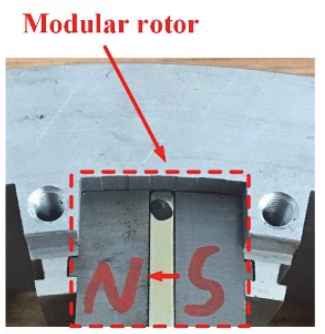

(a)

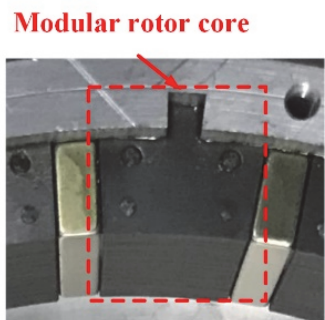

(b)
Fig. 15. Basic modules in MSTPM machines. (a) M-I. (b) M-II.

\section{Prototype Machines}

In Fig. 15, the basic modules of two types of MSTPM machines are illustrated. For the M-I MSTPM machine, each single piece of magnet and two pieces of rotor teeth are made into an elementary rotor module. Then the rotor module is inserted into the aluminum rim. However, in the two M-II MSTPM machines, all magnets are inserted (or hammered) in the rotors after all rotor teeth are inserted into the aluminum rims. It should be noted that an interference-fit-designed dovetail slot structure is applied to insert all rotor teeth into aluminum rims in all three MSTPM machines. Besides, all possible gaps are filled with high-quality anaerobic adhesive to avoid any shedding. The armature coils are wound by hand around the stator teeth with a winding packing factor of 0.35 .

The experimental platform also includes a controllable load (a magnetic powder brake), a digital oscilloscope (Agilent MSO-X 3024A), a 3-phase permanent magnet synchronous machine (PMSM) controller, and a DC power supply (KIKUSUI PAT250-32T).

\section{J. Open-Circuit Test}

In Figs, 16 and 17, the tested phase-to-phase (line) back-EMF waveforms (at the rated speed of $480 \mathrm{r} / \mathrm{min}$ ) and corresponding harmonic spectra of three manufactured MSTPM prototype machines are illustrated. It is found that the M-II MSTPM machine with the laminated rotor has the highest line back-EMF. The machine with solid-iron-made rotor has a lower back-EMF than the machines with laminated rotor due to the lower permeability of the solid iron. The FEA-calculated line back-EMF of M-I and M-II MSTPM machines are $64 \mathrm{~V}$ and $65.8 \mathrm{~V}$, respectively, and the tested results are $63.5 \mathrm{~V}$ and $65 \mathrm{~V}$, thus a good agreement is achieved. The predicted and measured back-EMF and inductance are listed in Table VII. A good agreement was achieved.

TABLE VII

Static Characteristics OF PROTOTYPED MaChines

\begin{tabular}{ccccc}
\hline \hline \multirow{2}{*}{ Parameter } & \multicolumn{2}{c}{ M-I } & \multicolumn{2}{c}{ M-II (Laminated } \\
rotor) \\
& Predicted & Measured & Predicted & Measured \\
\hline $\begin{array}{c}\text { Fundamental line } \\
\text { back-EMF }\end{array}$ & $64 \mathrm{~V}$ & $63.5 \mathrm{~V}$ & $65.8 \mathrm{~V}$ & $65 \mathrm{~V}$ \\
$L_{d}$ & 0.216 & $0.215 \mathrm{mH}$ & $0.304 \mathrm{mH}$ & $0.295 \mathrm{mH}$ \\
$L_{q}$ & $\mathrm{mH}$ & $0.24 \mathrm{mH}$ & $0.417 \mathrm{mH}$ & $0.4 \mathrm{mH}$ \\
\hline \hline
\end{tabular}

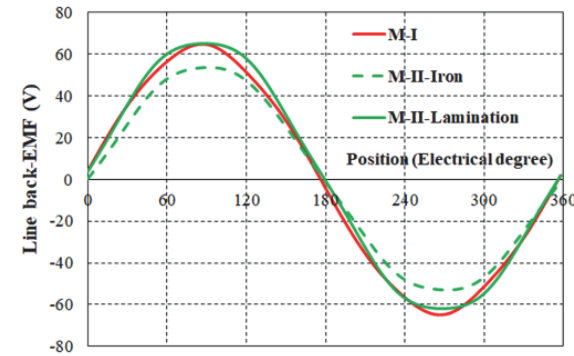

Fig. 16. Tested line back-EMF waveforms of three MSTPM machines.

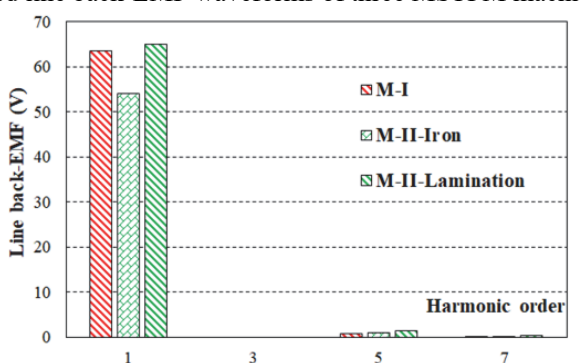

Fig. 17. Tested line back-EMF harmonic spectra of three MSTPM machines.

\section{K. On-Load Test}

The on-load test results including the torque-speed curve with rated $30 \mathrm{~A}(\mathrm{RMS})$ current injection, efficiency-speed curve with rated $30 \mathrm{~A}(\mathrm{RMS})$ current injection, and torque-current curve, are shown in Figs. 18, 19, and 20 respectively. It is found that the M-II MSTPM machine with laminated rotor produces the highest torque with the highest efficiency in the constant-torque region, which concurs with the FEA-predicted results. Besides, the M-I MSTPM machine has a wider speed range than the M-II MSTPM machine with laminated rotor. The M-II MSTPM machine with iron-made rotor produces the least torque because of the lowest back-EMF.

The rated and highest efficiency of the M-I MSTPM machine are $85 \%$ and $89 \%$ (at $600 \mathrm{r} / \mathrm{min}$ ), while for the M-II MSTPM machine with laminated rotor these are $91.8 \%$ and $91.8 \%$ (at 480 $/ \mathrm{min}$ ) respectively, which are close to the FEA-predicted results. Due to the heavy eddy current losses, the M-II MSTPM machine with solid-iron-made rotor has the lowest efficiency.

From Fig. 20, it is found that both the M-II MSTPM machines with laminated and solid-iron-made rotor have quite a linear torque-current curve. Although the M-II MSTPM machine with solid-iron-made rotor produces a lower torque than the M-I MSTPM machine in the low-current region $(<110 \mathrm{~A})$, the situation reverses when current is higher than 110 A. Hence, the M-II MSTPM machine with solid-iron-made rotor is a better choice than the M-I MSTPM machine with laminated rotor for applications where very high torque/current density is required at a low cost. Overall, the M-II MSTPM machine with laminated rotor exhibits the best over-load capability, which is consistent with the FEA-predicted results. 


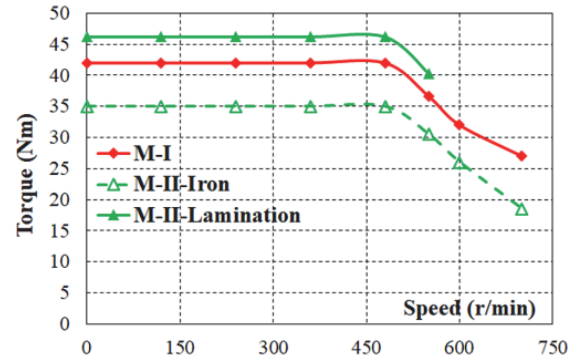

Fig. 18. Tested torque-speed curves of three MSTPM machines with 30A phase current (RMS) injection.

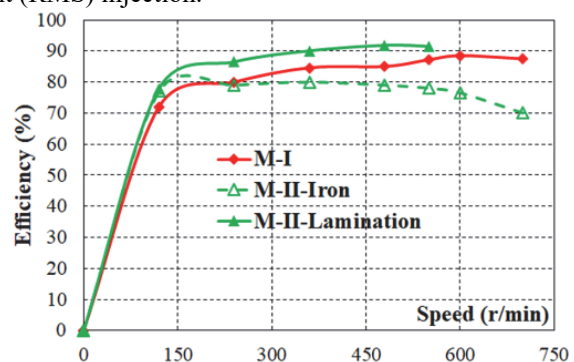

Fig. 19. Tested efficiency-speed curves of three MSTPM machines with 30A phase current (RMS) injection.

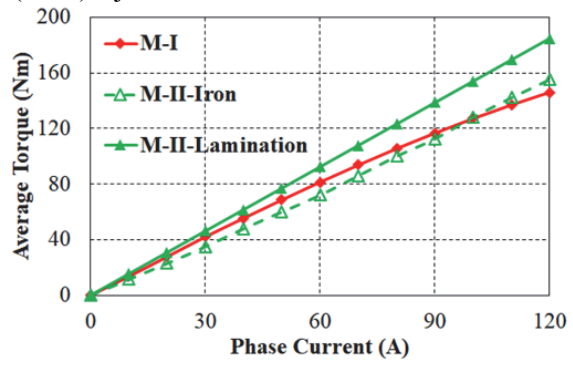

Fig. 20. Tested torque-current curves of three MSTPM machines.

\section{CONCLUSION}

In this paper, the MSTPM machines with two different magnetization modes referred to as M-I and M-II types, are modeled and compared. First, the machine topologies with different magnetization modes are introduced. Then, the magnetic circuit models and PM-MMF-permeance models of M-I and M-II MSTPM machines are built, which results in an analytical solution of both air-gap flux density and torque-sizing equation. According to the analytical model, it is found that M-I and M-II MSTPM machines have different optimal rotor structure in order to achieve the highest torque density. Furthermore, based on the analytical and FEA models, two M-I and M-II MSTPM machines are designed for an electric motorcycle application and compared in detail with respect to the split ratio, back-EMF, inductance, cogging torque, average torque, efficiency, and over-load capability. Three prototype machines are manufactured and tested to verify the prediction. It is concluded that the M-I MSTPM machines exhibit a better flux-weakening capability and wider speed range, while the M-II MSTPM machines have a superior efficiency, torque output, and over-load performance. This paper is an effective and practical reference for the design of MSTPM machines for in-wheel traction applications.

\section{APPENDIX}

To discover which one of pole-pair number and magnetization mode contributes more to the performance difference, an M-II MSTPM machine with 52 pieces of magnets was designed and compared with the two M-I and M-II MSTPM machines designed in Section III. For the sake of fairness, the third case has the same split ratio and number of turns per phase as the M-II MSTPM machine with 26 pieces of magnets. From Table VIII, both M-II MSTPM machines feature higher torque, higher torque density, higher efficiency, but worse flux-weakening capability and narrower constant-power region than the M-I MSTPM machine. The results reveal that the magnetization mode contributes more to the performance difference.

TABLE VIII

PERFORMANCE COMPARISON OF THREE MSTPM MACHINES

\begin{tabular}{cccc}
\hline \hline Performance & M-I & M-II & $\begin{array}{c}\text { M-II (third } \\
\text { case) }\end{array}$ \\
\hline Magnet number & 26 & 26 & 52 \\
Pole-pair number & 26 & 13 & 26 \\
Torque (30A) & $42 \mathrm{Nm}$ & $48 \mathrm{Nm}$ & $53.5 \mathrm{Nm}$ \\
Rated speed & $480 \mathrm{r} / \mathrm{min}$ & $480 \mathrm{r} / \mathrm{min}$ & $450 \mathrm{r} / \mathrm{min}$ \\
Power (rated) & $2.1 \mathrm{~kW}$ & $2.4 \mathrm{~kW}$ & $2.5 \mathrm{~kW}$ \\
Torque density (rated) & $15.6 \mathrm{Nm} / \mathrm{L}$ & $17.8 \mathrm{Nm} / \mathrm{L}$ & $19.8 \mathrm{Nm} / \mathrm{L}$ \\
Power density (rated) & $0.78 \mathrm{~kW} / \mathrm{L}$ & $0.89 \mathrm{~kW} / \mathrm{L}$ & $0.93 \mathrm{~kW} / \mathrm{L}$ \\
Magnet mass & $0.67 \mathrm{~kg}$ & $1.05 \mathrm{~kg}$ & $1.06 \mathrm{~kg}$ \\
Efficiency (rated speed) & $89 \%$ & $93.4 \%$ & $90 \%$ \\
Power factor (rated & 0.93 & 0.97 & 0.97 \\
speed) & 0.32 & 0.22 & 0.17 \\
$L_{d}$ (per-unit value) & 0.36 & 0.30 & 0.2 \\
$L_{q}$ (per-unit value) & $480 \sim 750$ & $480 \sim 550$ & $450 \sim 480 \mathrm{r} / \mathrm{min}$ \\
Constant-power region & $\mathrm{r} / \mathrm{min}$ & $\mathrm{r} / \mathrm{min}$ & \\
\hline \hline
\end{tabular}

\section{REFERENCES}

[1] J. B. Wang, K. Atallah, Z.Q. Zhu, and D. Howe, "Modular three-phase permanent-magnet brushless machines for in-wheel applications," IEEE Trans. Veh. Technol., vol.57, no.5, pp. 2714-2720, Sep. 2008.

[2] W. Fei, P. C. K. Luk, J. X. Shen, Y. Wang, and M. Jin, "A novel permanent-magnet flux switching machine with an outer-rotor configuration for in-wheel light traction applications," IEEE Trans. Ind. Appl., vol.48, no.5, pp.1496-1506, Sep./Oct. 2012.

[3] C. J. Ifedi, B. C. Mecrow, S. T. M. Brockway, G. S. Boast, G. J. Atkinson, and D. K. Perovic, "Fault-tolerant in-wheel motor topologies for high-performance electric vehicles," IEEE Trans. Ind. Appl., vol.49, no.3, pp.1249-1257, May/Jun. 2013.

[4] M.T. Peng, and T.J. Flack, "Design and analysis of an in-wheel motor with hybrid pole-slot combination," IEEE Trans. Magn., vol.52, no.6, Jun. 2016. Article \#:8202308.

[5] W. Fei, P. C. K. Luk, D.-M. Miao, and J. X. Shen, "Investigation of torque characteristics in a novel permanent magnet flux switching machine with an outer-rotor configuration," IEEE Trans. Magn., vol.50, no.4, pp.1-10, Apr. 2014.

[6] X. D. Xue, K.W.E. Cheng, T.W. Ng, and N.C. Cheung, "Multi-objective optimization design of in-wheel switched reluctance motors in electric vehicles," IEEE Trans. Ind. Electron., vol.57, no.9, pp. 2980-2987, Sep. 2010.

[7] S.G. Zuo, F. Lin, and X.D. Wu, "Noise analysis, calculation, and reduction of external rotor permanent-magnet synchronous motor," IEEE Trans. Ind. Electron., vol.62, no.10, pp. 6204-6212, Oct. 2015.

[8] Y. Fan, L. Zhang, J. Huang, and X.D. Han, "Design, analysis, and sensorless control of a self-decelerating permanent-magnet in-wheel motor," IEEE Trans. Ind. Electron., vol.61, no.10, pp. 5788-5797, Oct. 2014.

[9] Y. F. Wang, H. Fujimoto, and S. Hara, "Driving force distribution and control for electric vehicles with four in-wheel motors: a case study of acceleration on split-friction surfaces," IEEE Trans. Ind. Electron., vol.64, no.4, pp. 3380-3388, Apr. 2017. 
[10] A. J. Rix, and M. J. Kamper, "Radial-flux permanent-magnet hub drives: a comparison based on stator and rotor topologies," IEEE Trans. Ind. Electron., vol.59, no.6, pp. 2475-2483, Jun. 2012.

[11] S. U. Chung, S. H. Moon, D. J. Kim, and J. M. Kim, "Development of a 20-pole-24-slot SPMSM with consequent pole rotor for in-wheel direct drive," IEEE Trans. Ind. Electron., vol.63, no.1, pp. 302-309, Jan. 2016.

[12] C. H. T. Lee, K. T. Chau, C. H. Liu, T. W. Ching, and F. H. Li, "A high-torque magnetless axial-flux doubly salient machine for in-whee direct drive applications," IEEE Trans. Magn., vol.50, no.11, Nov. 2014. Article \#:8202405

[13] Y. B. Wang, Q. Feng, X. L. Li and W. Z Ma. "Design, analysis, and experimental test of a segmented-rotor high temperature superconducting generator with stationary seal," IEEE Trans. Ind. Electron., vol.65, no.11, pp. 9047-9055, Nov. 2018

[14] W. Hua, H. L. Zhang, M. Cheng, J. J. Meng, and C. Hou, "An outer-rotor flux-switching permanent-magnet-machine with wedge-shaped magnets for in-wheel light traction," IEEE Trans. Ind. Electron., vol.64, no.1, pp 69-80, Jan. 2017

[15] X. Y. Zhu, Z. M. Shu, L. Quan, Z. X. Xuan, and X. Q. Pan, "Design and multicondition comparison of two outer-rotor flux-switching permanent-magnet motors for in-wheel traction applications," IEEE Trans. Ind. Electron., vol.64, no.8, pp. 6137-6148, Aug. 2017.

[16] K. Kiyota and A. Chiba, "Design of Switched Reluctance Motor ompetitive to 60-kW IPMSM in Third-Generation Hybrid Electric Vehicle," IEEE Trans. Ind. Appl., vol. 48, no. 6, pp.2303-2309, Nov./Dec. 2012

[17] H. L. Zhang, and W. Hua, "A novel outer-rotor-permanent-magnet flux-switching machine for in-wheel light traction," in Proc. IEEE-IECON, Florence, Italy, Oct. 2016, pp. 6633-6638.

[18] H. L. Zhang, W. Hua, and Z. Z. Wu, "Modular spoke-type permanent-magnet machine for in-wheel traction applications," IEEE Trans. Ind. Electron., vol.65, no.10, pp.7648-7659, Oct.2018.

[19] H. L. Zhang, W. Hua, and G. Zhang, "Analysis of back-EMF waveform of a novel outer-rotor-permanent-magnet flux-switching machine," IEEE Trans. Magn., vol.53, no.6, Jun. 2017. Article \#:8105004.

[20] H. L. Zhang, W. Hua, and X.K. Zhu, "Design of novel modular-spoke-type permanent magnet machines," in Proc. IEEE-IEMDC, Miami, USA, May 2017.

[21] H. L. Zhang, W. Hua, Z. Z. Wu, and X. K. Zhu, "Design considerations of novel modular-spoke-type permanent magnet machines," IEEE Trans. Ind. Appl., vol.54, no.5, pp.4236-4245, Sep./Oct. 2018.

[22] H. L. Zhang, and W. Hua, "The influence of magnetization on modular spoke-type permanent-magnet machine for in-wheel traction applications," IEEE Trans. Magn., vol. 54, no. 11, Nov. 2018. Article \#:8105105.

[23] Z. Q. Zhu, Y. Pang, D. Howe, S. Iwasaki, R. Deodhar, and A. Pride, "Analysis of electromagnetic performance of flux-switching permanent-magnet machines by nonlinear adaptive lumped parameter magnetic circuit model," IEEE Trans. Magn., vol.41, no.11, pp.4277-4287, Nov. 2005.

[24] T. A. Lipo, Introduction to AC Machine Design, Wisconsin Powe Electronics Research Center, University of Wisconsin-Madison, 2011.

[25] M. Cheng, P. Han, and W. Hua, "A general airgap field modulation theory for electrical machines," IEEE Trans. Ind. Electron., vol.64, no.8, pp.6063-6074, Aug. 2017.

[26] Z. Z. Wu, and Z. Q. Zhu, "Analysis of air-gap field modulation and magnetic gearing effects in switched flux permanent magnet machines," IEEE Trans. Magn., vol.51, no.5, May 2015. Article \#:8105012.

[27] Z. Q. Zhu, and Y. Liu, "Analysis of air-gap field modulation and magnetic gearing effect in fractional-slot concentrated-winding permanent-magnet synchronous machines," IEEE Trans. Ind. Electron., vol.65, no.5, pp.3688-3698, May 2018.

[28] K. J. Binns, and P. J. Lawrenson, Analysis and Computation of Electric and Magnetic Field Problems, 2nd ed. Oxford, U.K.: Pergamon Press, 1973.

[29] Y. Yokoi, T. Higuchi, and Y. Miyamoto, "General formulation of winding factor for fractional concentrated winding design," IET Electr. Power Appl., vol.10, no.4, pp. 231-239, Apr. 2016.

[30] X. F. Zhu, W. Hua, Z. Z. Wu, W. T. Huang, H. L. Zhang, and M. Cheng, "Analytical approach for cogging torque reduction in flux-switching permanent magnet machines based on magneto motive force-permeance model," IEEE Trans. Ind. Electron., vol.65, no.3, pp.1965-1979, Mar. 2018

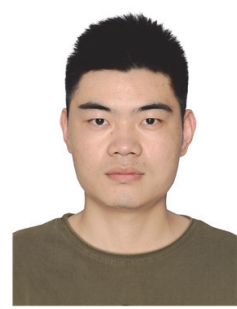

Hengliang Zhang was born in Anhui, China, in 1992. $\mathrm{He}$ received the B.Sc. degree in electrical engineering from Southeast University, Nanjing, China, in 2014. He is currently working toward the $\mathrm{Ph} . \mathrm{D}$. degree in electrical engineering with the School of Electrical Engineering, Southeast University, Nanjing, China. From 2018 to 2019, he was with the Power Electronics, Machines and Control Group, The University of Nottingham, Nottingham, U.K., as a Joint-Supervised Ph.D. Student. His research interests include the electromagnetic design, and thermal analysis of permanent magnet machines.

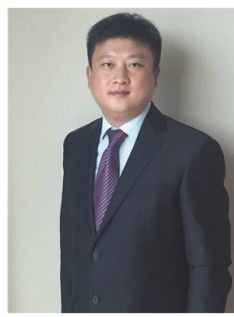

Wei Hua (SM'16) was born in Taizhou, China, in 1978 He received the B.Sc. and Ph.D. degrees in electrical engineering from Southeast University, Nanjing, China, in 2001 and 2007, respectively. From 2004 to 2005, he was with the Department of Electronics and Electrical Engineering, The University of Sheffield, U.K., as a Joint-Supervised Ph.D. Student. Since 2007, he has been with Southeast University, where he is currently a Professor with the School of Electrical Engineering. He has authored or coauthored over 150 technical papers. He holds 50 patents in his areas of interest. His teaching and research interests include the design, the analysis, and the control of electrical machines.

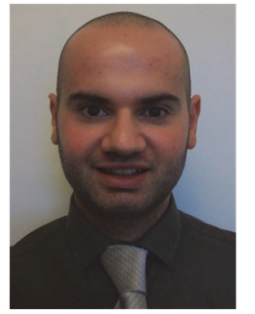

David Gerada received the Ph.D. degree in high-speed electrical machines from the University of Nottingham, Nottingham, UK in 2012. From 2007-2016 he was with the R\&D Department at Cummins, first as an Electromagnetic Design Engineer (2007-2012), and then as a Senior Electromagnetic Design Engineer and Innovation Leader (2012-2016). At Cummins he pioneered the design and development of high-speed electrical machines, transforming a challenging technology into a reliable one suitable for the transportation market, while establishing industry-wide used metrics for such machinery. In 2016 he joined the University of Nottingham as a Senior Fellow in Electrical Machines, responsible for developing state of the art electrical machines for future transportation which push existing technology boundaries, while propelling the new technologies to higher technology readiness levels (TRL). Dr. Gerada is a Chartered Engineer in the U.K. and a member of the Institution of Engineering and Technology.

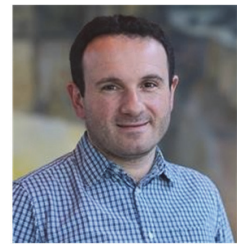

Chris Gerada is an Associate Pro-Vice-Chancellor for Industrial Strategy and Impact and Professor of Electrical Machines. His principal research interest lies in electromagnetic energy conversion in electrical machines and drives, focusing mainly on transport electrification. He has secured over $£ 20 \mathrm{M}$ of funding through major industrial, European and UK grants and authored more than 350 referred publications. He received the Ph.D. degree in numerical modelling of electrical machines from The University of Nottingham, Nottingham, U.K., in 2005. He subsequently worked as a Researcher with The University of Nottingham on high-performance electrical drives and on the design and modelling of electromagnetic actuators for aerospace applications. In 2008, he was appointed as a Lecturer in electrical machines; in 2011, as an Associate Professor; and in 2013, as a Professor at The University of Nottingham. He was awarded a Research Chair from the Royal Academy of Engineering in 2013. Prof. Gerada served as an Associate Editor for the IEEE TRANSACTIONS ON INDUSTRY APPLICATIONS and is the past Chair of the IEEE IES Electrical Machines Committee.

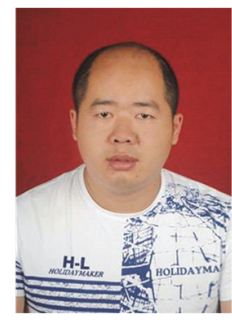

Yugang Li received the Master degree in Precision Instrument and Machinery from Changchun University of Science and Technology, Changchun, China, in 2006. $\mathrm{He}$ is currently with Wuxi Sine Power Technology Co., Ltd.

His research interests include the design, and optimization of permanent magnet machines. 
Guang Zhang received the Bachelor degree in Mechanical Engineering from Jiujiang University, Jiujiang, China, in 2008. He is currently with Wuxi Sine Power Technology Co., Ltd.

His research interests include the design, and optimization of permanent magnet machines. 